\title{
The bears are right: Why cap-and-trade yields greater emission reductions than expected, and what that means for climate policy
}

\author{
Endre Tvinnereim
}

Received: 12 December 2013 / Accepted: 16 October 2014 / Published online: 5 November 2014

(C) Springer Science+Business Media Dordrecht 2014

\begin{abstract}
Cap-and-trade, a regulatory instrument widely used to constrain greenhouse gas and other pollution, has recently been criticized for producing only small amounts of intended emission reductions. This paper looks at the empirical record of cap-and-trade since the beginning in 1995, and shows that emission targets have almost always been easier and cheaper to reach than expected. The five main reasons are generous targets, changes in economic output, fuel price movements, innovation, and complementary emission reduction policies. Overall, this failure to predict mitigation potentials may relate to a psychological "end of history bias," whereby policymakers, industry, and analysts think that less change will happen in the future than has demonstrably happened in the past. Consequently, more abatement is possible and at lower costs than generally thought, rendering the prices of emission permits hard to predict. For climate research, the findings imply that emission scenarios assuming ever-increasing pollution prices may benefit from integrating recent experience with cap-and-trade regulations. In policy terms, mechanisms such as floor prices need to be considered to guarantee emission reductions under uncertainty.
\end{abstract}

\section{Introduction}

Cap-and-trade programs have been introduced on four continents to reduce harmful greenhouse gas (GHG) emissions. While the compliance record is stellar as companies overwhelmingly follow the regulations, tradable permit prices have overall been lower than originally predicted (Laing et al. 2013). In market speech, "bulls" are those who expect higher prices, whereas "bears" are those who expect them to fall. In emission markets so far, the bears have been right.

Electronic supplementary material The online version of this article (doi:10.1007/s10584-014-1282-1) contains supplementary material, which is available to authorized users.

E. Tvinnereim $(\bowtie)$

Uni Research Rokkan Centre, Nygårdsgaten 5, 5015 Bergen, Norway

e-mail: endre.tvinnereim@uni.no 
At the same time, it is not a given that low emission prices stem exclusively from low ambition. In politically constructed emission markets, prices are influenced both by expectations of the need for reductions (demand) and the ability to reduce at given prices (supply). The exact contribution of each is indeterminate, but low prices may as well signify easy cuts as easy targets. Easy reductions would be good news in a world worried about GHG trends and how to bear the costs of mitigation.

Why is this important? First, cap-and-trade is arguably the most comprehensive type of climate change mitigation policy currently in place, judging by dimensions such as coverage, ambition, and duration. At the same time, the widespread discontent with low prices imply a serious challenge to the continued existence of this policy instrument, offering a choice between careful reform and obsolescence.

Second, current theory about the relationship between emissions and carbon price levels may benefit from integrating empirical evidence on abatement potentials and price discovery from cap-and-trade regulations around the world. For example, $\mathrm{CO}_{2}$ emission prices constitute an important component of models used by the Intergovernmental Panel on Climate Change (IPCC). This paper suggests that ever-rising carbon prices may not be a necessary component of global climate policy, at least not in the major emitting sectors typically covered by cap-and-trade.

\section{Carbon pricing in theory and practice}

A dominant frame in the debate over human-made climate change has been the idea of a market failure (Stern 2007). Costs caused by GHG emissions are not borne in full by the emitters. A commonly used approach to this type of problem, first proposed by Pigou (1920), is to put a price on the harmful activity corresponding to the marginal damage it produces. In an ideal situation, emissions with low benefits would thus be phased out, whereas emissions associated with high value would be maintained.

Two main categories of pollution pricing mechanisms are found in regulations around the world: Taxes and cap-and-trade. The conventional view is that "Quantity targets guarantee a fixed level of emissions. Emission taxes guarantee a fixed financial incentive to reduce emissions" (Pizer 2001, 99). While carbon taxes are preferred by many economists and predate caps, they are less widely used and are today found mainly in the Scandinavian countries (since the early 1990s), the UK, and the Canadian province of British Columbia (Goulder and Schein 2013; Enevoldsen et al. 2007). By contrast, cap-and-trade is currently in place or in the process of being set up in the EU, ten US states, the city of Tokyo, South Korea, the Canadian province of Quebec, several Chinese provinces, and internationally through the Kyoto Protocol. In the US, cap-and-trade has been used to limit non-GHG pollutants such as sulfur dioxide $\left(\mathrm{SO}_{2}\right)$ and nitrogen oxides $\left(\mathrm{NO}_{x}\right)$ since 1995.

Cap-and-trade is a regulatory instrument designed to lower the cost of meeting a given emission target by setting an aggregate maximum emission level (the cap). Having determined the total cap for a range of years into the future, the system then leaves it to covered firms to decide where emissions will come from using a system of tradable permits or "allowances." An allowance is a permit to pollute, typically representing one ton of emissions.

The cap-and-trade cycle starts with the regulator, who sets the maximum level of pollution (the "cap") and distributes permits to pollute accordingly. Permits or "allowances" may either be given away for free or sold. At the end of each compliance period, typically 
every year, participating firms are required to surrender an amount of allowances corresponding to the verified emission totals from their covered activities. Firms may sell unused permits to others who might need them, or they may save ("bank") them into future years, in anticipation of potentially higher demand, fuel price fluctuations or other changes to the firm's circumstances. This flexibility to bank is one of the most important features of capand-trade, as it gives companies a longer time horizon for managing their emissions while reducing price volatility (Ellerman et al. 2003).

The purposes of cap-and-trade may be defined narrowly or broadly. The narrow success criterion states that emission targets need to be met, ideally at a relatively low price to society, or "with the least possible diminution of economic development and employment," as stated the EU ETS directive (European Parliament and Council of the European Union 2003, paragraph 5).

A wider set of expectations from cap-and-trade includes the establishment of frameworks for long-term carbon price signals (if not necessarily stable in terms of price levels), incentivizing investment in clean energy and low-carbon production. Clean energy investment, in turn, is expected to drive both innovation and job growth. For example, the seven founding states of the US Regional Greenhouse Gas Initiative (RGGI) in 2005 envisioned that a carbon cap with trading would generate "a strong incentive for the creation, development, and deployment of more efficient fuel burning technologies and processes, as well as renewable energy supplies, demand-side management practices and actions to increase energy efficiency" (Regional Greenhouse Gas Initiative 2005, paragraph 4). Media reports also frequently see substantial allowance prices as a necessary condition for success (Reed 2013).

While over a dozen cap-and-trade programs have been introduced around the globe to address local, regional, and global pollution issues, seven stand out due to their scope, duration, and facilities to trade. These are the US Acid Rain Program (ARP), the Ozone Transport Commission (OTC), the $\mathrm{NO}_{x}$ Budget Program/Clean Air Interstate Rule $\left(\mathrm{NBP} / \mathrm{CAIR} \mathrm{NO}_{x}\right.$ ), the EU Emission Trading Scheme (ETS), the Kyoto Protocol, the Regional Greenhouse Gas Initiative (RGGI), and the Tokyo Emission Trading Scheme. ${ }^{1}$ Of these, the ARP targets $\mathrm{SO}_{2}$, the OTC and NBP/CAIR programs limit emissions of $\mathrm{NO}_{x}$ while the remaining programs regulate GHGs.

These cap-and-trade regulations have existed for a total of 49 program-years. It is thus possible to compare emissions to the cap in each of those years to assess whether the programs' intentions have been fulfilled and the degree to which emissions have been fixed in each case. Figure 1 shows the distribution of these quotients.

The tendency is clear: Emissions are well below the cap on average. Specifically, the mean emission level expressed as a share of the annual cap is 85 percent. Cap-and-trade thus produces no "fixed" emission level but rather a consistent over-compliance with emission targets. Furthermore, based on the same data as the previous chart, Fig. 2 shows that the

\footnotetext{
${ }^{1} \mathrm{~A}$ few early emission trading systems in the US have been excluded, see Ellerman et al. (2003) for an overview. Furthermore, emission trading systems without a firm cap, such as the New Zealand Emission Trading Scheme and the New South Wales Greenhouse Gas Abatement Scheme, have been kept out from this study. It is too early to evaluate the Californian (started 2013) and South Korean (to launch in 2015) capand-trade programs. Finally, the paper will not analyze transitional programs such as the Danish, UK, and Norwegian emission trading systems. Available evidence suggests that emissions have generally been lower than expected also in other cases, see Daley and Edis (2010). However, data availability and varying rules make comparison difficult.
} 


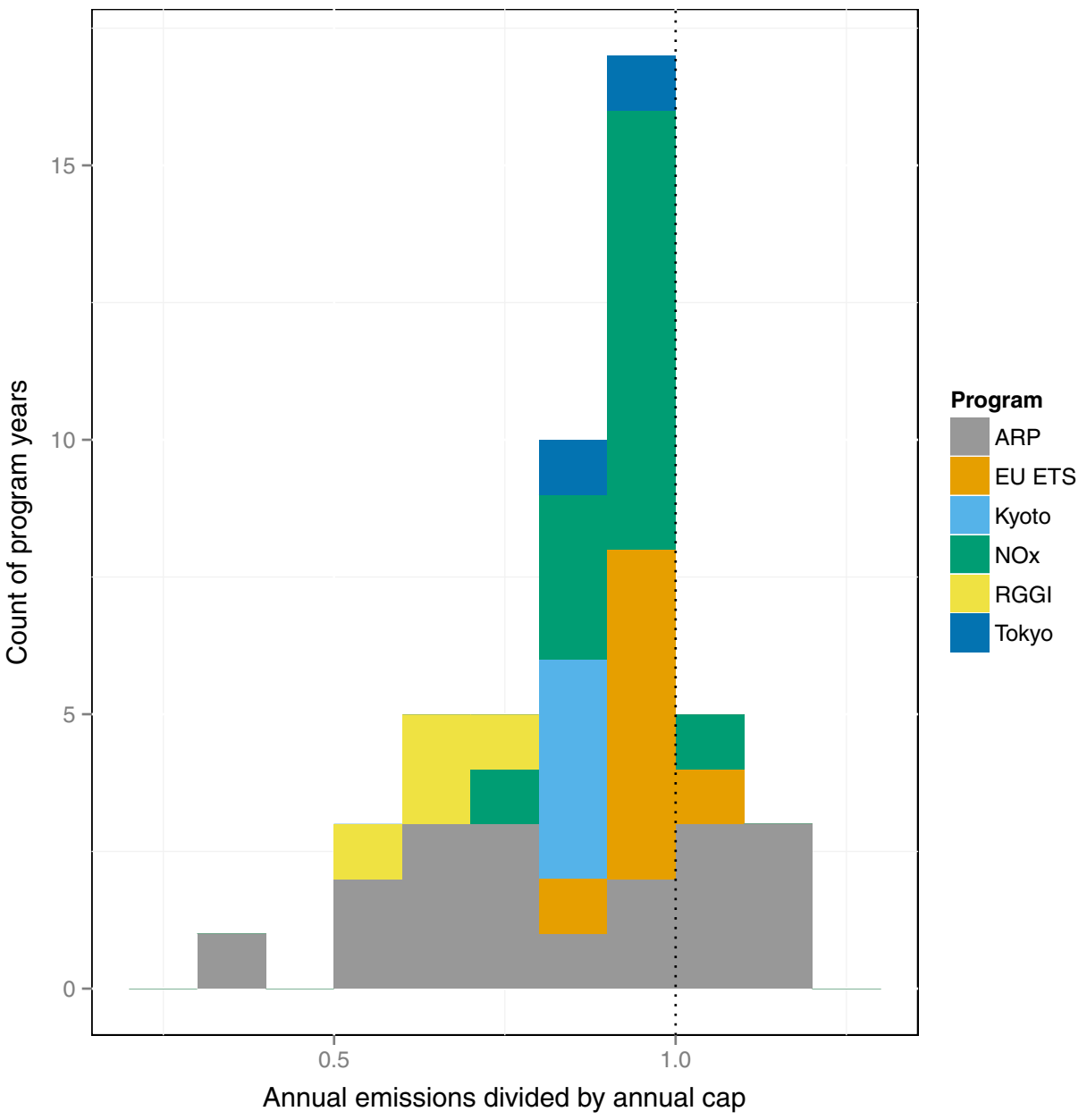

Fig. 1 Distribution of emissions to cap ratios. Emissions divided by allowance issuance (the sum of free permits and auctions) in the six most prominent cap-and-trade programs with at least two years of history. Annual data. Data sources: US EPA, European Commission, UNFCCC, Tokyo Metropolitan Government, Point Carbon, RGGI Inc

gap between annual caps and annual emissions tends to widen by about one-half of one percentage point per year.

\section{Why are emission levels lower than expected?}

Why do emissions fall far below the cap so often? Laing et al. (2013) list three types of factors: External, such as recession; revelation, such as when business-as-usual emissions turn out to have been overestimated; and unexpected responses by industries such as cement to generate innovative abatement methods. This paper will examine these and two additional explanations: Changes in fuel prices and complementary policies to reduce emissions. 
A first explanatory factor is the generous determination of caps. Emission permits are valuable assets that may be distributed by policymakers to companies to lighten the burden of imposed emission restrictions. However, it remains a challenge to make a cap tight enough to ensure real reductions but not so tight as to extinguish vital economic activity, forcing industry out of one's jurisdiction and risking a political backlash. Finding an acceptable level for the cap is particularly difficult when emission baselines are poorly known. In such cases, policymakers are likely to err on the side of generosity toward industry.

Second, economic output tends to correlate with GHG emissions. Thus, a recession means that emissions fall amid reduced demand for electricity, fuels, cement, and metals. As emissions decline, fewer participants in cap-and-trade systems need to buy permits to comply with the regulation, while more participants are able to sell surplus permits released due to lower production-related emissions.

Third, relative fuel price movements affect emission levels in cap-and-trade programs to the extent that emitters are in a position to choose between fuel types with different emission rates. For example, switching to coal with lower sulfur content is an alternative to installing scrubbers to reduce $\mathrm{SO}_{2}$ emissions. Switching from coal to gas in power stations reduces $\mathrm{CO}_{2}$ emissions by about half.

Unexpected innovations in emission abatement constitute a fourth factor that may cause emissions targets to be reached more easily than expected. Some changes in technologies, processes, and practices may be anticipated at the outset of a cap-and-trade program, but others may appear as more attention is directed toward emission reduction. Examples are the use of low-carbon alternative products in the cement industry and the development of new scrubbers to reduce $\mathrm{SO}_{2}$ emissions. While some innovation is foreseen in long-term scenarios for deep emission reductions, notably in the form of biomass carbon capture and storage (Kriegler et al. 2014), new and unanticipated abatement methods are by definition hard to quantify in advance, producing a conservative bias in the emission projections used by policymakers.

A fifth and final factor explaining why emissions tend to fall below the cap is constituted by policies complementary to cap-and-trade programs. Important policies in this category are renewable energy support systems such as feed-in tariffs and renewable portfolio standards. Measures to curb urban air pollution, additional taxes and emission or efficiency standards also pull in the same direction as cap-and-trade. A consequence of complementary policies of this type is that the additional emission reductions blunt the independent effect of the cap-and-trade regulation, as demand as well as prices for allowances fall.

\section{The empirical record of unanticipated emission reductions}

\subsection{Acid rain program (1995-)}

The Acid Rain Program (ARP) covers $\mathrm{SO}_{2}$ emissions from US power plans burning fossil fuels. The first phase of the program (1995-99) covered 263 electricity generating facilities and saw emissions capped at a declining volume from 8.7 million tons (Mt) to 7.0 Mt/year (Ellerman et al. 2003). The second phase, starting in 2000 and with no end date, imposed a cap converging on $9.5 \mathrm{Mt} /$ year until 2010, when a final, fixed statutory cap of $8.95 \mathrm{Mt} /$ year was introduced. More than 2,000 facilities were brought under the ARP cap in the second phase.

Actual emissions from covered facilities in phase 1 were much lower than the cap, which led to the buildup of a significant cumulative surplus or allowance bank of $21.6 \mathrm{Mt}$ by 2000 


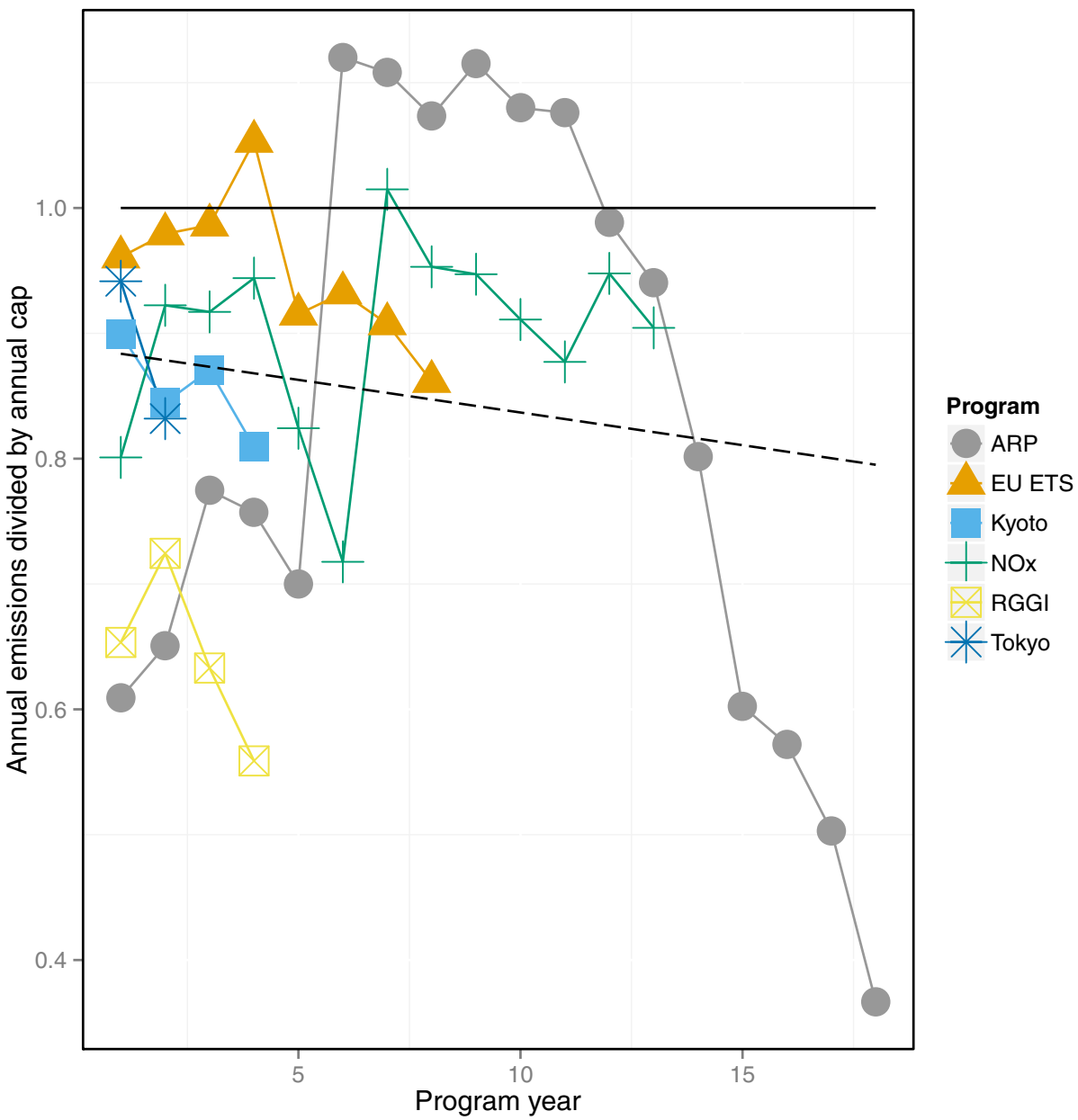

Fig. 2 Emissions to cap ratios over time. The figure shows annual emissions divided by annual allowance issuance (the sum of free and auctioned allowances) in the six most prominent cap-and-trade programs with at least two years of history. For visibility purposes, the US NOx programs and the phases of the EU ETS have been collapsed into two lines. A trend line is shown. A ratio of one (solid line) means that emissions equal the cap in the given year. Data sources: US EPA, European Commission, UNFCCC, Tokyo Metropolitan Government, Point Carbon, RGGI Inc

(United States Environmental Protection Agency 2009). The surplus was partly due to the anticipation of what was perceived as more stringent caps in the second phase, prompting firms to take early action to save allowances for future use, and partly due to firms with low abatement costs opting into the system to earn allowances (Ellerman et al. 2003). This bank began to be drawn down after the start of Phase 2, as emissions exceeded the annual cap in the years 2000-2005 (see Fig. 2). From 2006, emissions again fell below the cap, causing the bank to increase every year thereafter.

What made the initial surplus possible, and why did the bank soar from 2008 and onwards? Schmalensee and Stavins (2012) point to technological innovation and a quickly maturing market in the years following 1995, as electricity generators sought to build up an 
allowance cushion ahead of stricter requirements in phase 2. At the same time, rail deregulation in 1976 and 1980 reduced freight rates for low-sulfur coal from Wyoming and Montana to power plants east of the Mississippi. The new coal supplies meant that some operators would have lowered their sulfur emissions even without the ARP.

From 2008, however, demand for $\mathrm{SO}_{2}$ allowances started to decline following unsuccessful attempts to tighten the $\mathrm{SO}_{2}$ cap and court rulings stating that unlimited interstate $\mathrm{SO}_{2}$ emission trading led to unacceptably high local emission levels in some states. As individual states had to reduce pollution within their own boundaries, for example by demanding the use of scrubbers or shutting down plants, the interstate market essentially died (Schmalensee and Stavins 2012). Thus, even as the ARP $\mathrm{SO}_{2}$ cap-and-trade regulation remains in force it no longer influences $\mathrm{SO}_{2}$ emission levels across the US in any meaningful way.

\subsection{US NO $x$ programs (1999-)}

Efforts to reduce ozone pollution emerged in states in the US Northeast in the 1980s. Ozone pollution at the ground level is formed when $\mathrm{NO}_{x}$ and volatile organic compounds (VOCs) react with sunlight. Ozone increases the symptoms of respiratory illnesses and asthma, and damages plants and buildings (United States Environmental Protection Agency 2003).

The first cap-and-trade program to control $\mathrm{NO}_{x}$ emissions was set up by states from Maryland to Maine, plus parts of the Washington, D. C. metropolitan area. The cap-andtrade program was set up under the Ozone Transport Commission (OTC), a wider effort to limit ozone pollution in the region (Carlson 2009). This initial cap-and-trade program, called the OTC $\mathrm{NO}_{x}$ Budget Program (OTC NBP) covered large electricity producers and industrial facilities starting in 1999.

The state-led OTC NBP was in 2003 replaced by a cap-and-trade program nested within the federal $\mathrm{NO}_{x}$ State Implementation Plan (SIP) Call from 1998. This program covered 20 states. $\mathrm{NO}_{x}$ cap-and-trade expanded further in 2009, with the Clean Air Interstate Rule (CAIR) and its $\mathrm{NO}_{x}$ ozone season program, which replaced the NBP in the East. CAIR covers 27 states and the District of Columbia, and caps both $\mathrm{SO}_{2}$ and $\mathrm{NO}_{x}$ emissions.

Both the OTC and the $\mathrm{NO}_{x}$ SIP call/CAIR programs experienced tight allowance market conditions and high prices in the beginning followed by later bank accumulation and lower prices (Burtraw and Szambelan 2009). High natural gas prices in 2003 led to more coal burning which caused higher $\mathrm{NO}_{x}$ emissions and allowance prices (United States Environmental Protection Agency 2009). Expansion of the program in 2004 to encompass new states introduced a large allowance surplus. A minor proportion of the bank was used in 2005 as emissions exceeded the cap by one percent, but from 2006, the bank grew continually as annual emissions remained comfortably below the cap.

What explains the widening gap between $\mathrm{NO}_{x}$ emissions and caps? In the case of the OTC, key factors are unexpected changes in the fuel mix, as nuclear power replaced coal, and better-than-expected performance of abatement technology due to the pre-existing and complementary regulation requiring the use of reasonably available control technology or RACT (United States Environmental Protection Agency 2004).

In the $\mathrm{NO}_{x}$ SIP call/CAIR program, small-scale modifications to existing power plants, fuel switching, and retirement of old power plants were important drivers. Switching from coal and oil to gas appears particularly important, as the use of gas increased by 65 percent from 2003 to 2008 (Burtraw and Szambelan 2009). Furthermore, complementary reduction efforts at regional and state levels also contributed "significantly" to emission cuts (United States Environmental Protection Agency 2012). 


\subsection{EU emission trading (2005-)}

The EU introduced a cap-and-trade system to help reach the collective European Kyoto target for 2008-12, after efforts to introduce an EU-wide carbon tax had failed. The EU ETS covers $\mathrm{CO}_{2}$ and nitrous oxide $\left(\mathrm{N}_{2} \mathrm{O}\right)$ emissions in sectors such as electricity, metals, cement, refineries, paper, and glass.

The initial three-year phase (2005-07) was designed as a test run, and permits issued for this period were not transferable to future periods. In the first phase, member states were in charge of the initial distribution of permits to industry. As the first batch of verified emission data was published in April 2006, showing much lower emissions than permitted under the aggregate cap, allowance prices crashed. The cap was subsequently lowered for the second (2008-12) phase, in line with the EU's collective Kyoto commitment. The tighter cap contributed to EU installations emitting more than the annual cap in 2008, forcing them to borrow from their 2009 allowance supply or to use external offset credits to remain in compliance. However, amid the global economic downturn, emissions in 2009 fell below the cap, where they have stayed. The market is likely to stay over-supplied for years to come, some analysts estimate until 2025 (Point Carbon 2014) As a response, the European Parliament in 2013 passed a measure to postpone or "back-load" the auctioning of some allowances, while starting a discussion about measures such as tightening the cap.

The first phase of the EU ETS constitutes a good example of generous cap determination based on insufficient information. Verified emission data were not available for most EU ETS companies before the launch of the program in 2005, and country caps were thus set largely based on projections. There is also reason to suspect an "upward bias introduced because the parties providing the data received allocations based on the same data" (Ellerman et al. 2010, 161).

While generous allocation was the primary reason for the unexpected ease of abatement in phase 1 , this may not be said for phase 2 . While a stricter phase 2 cap may have been set given the benefit of hindsight, the permitted emission level was calculated to a level reflecting the EU's target for the first Kyoto commitment period (2008-12), and was considered strict at the time.

The economic downturn that hit the market in 2008 is the main explanation for the unexpectedly low emissions in subsequent phases, and the accumulation of a large allowance bank (Laing et al. 2013). Industrial production fell, and along with it demand for electricity and thus the need to burn coal and gas. The housing market also contracted, reducing demand for steel and cement, two other carbon-intensive commodities.

Besides the recession, renewable energy subsidies have boosted power production from wind and solar, reducing the demand for allowances. In addition, innovation in emission abatement has played a role in the EU ETS. For example, cement production was not expected to contribute to emission cuts, but the sector nevertheless contributed to the abatement effort by fuel switching, notably from coal to waste and biomass, and by using alternatives to emissions-intensive clinker, such as fly ash (Laing et al. 2013).

\subsection{Kyoto Protocol (2008 - 12)}

The Kyoto Protocol to the UN Framework Convention on Climate Change (UNFCCC) was agreed in 1997 and entered into effect in 2005. At its heart lies an international cap-andtrade system. Countries classified as "developed" under the UNFCCC in 1992 were given 
emission targets for the five-year period from 2008 to 2012, normally expressed with reference to their 1990 emissions. Kyoto furthermore lets countries with emissions below their targets to sell surplus allowances to countries that struggle to reach theirs.

The initial thought behind the Kyoto market was that the US and other OECD countries would serve as a source of demand for surplus allowances from East European countries and carbon credits derived from projects in developing countries, including China and India. However, as the US withdrew from Kyoto in 2001, the market balance changed. In particular, Russia and Ukraine were left with huge allowance surpluses that did not have any prospects of being purchased in full.

These surpluses originated in skilful and persistent bargaining by Russia and Ukraine, which ensured them Kyoto allowances corresponding to their full 1990 emission levels, even though their industrial output and emissions had plummeted (Grubb 2003; Henry and Sundstrom 2010). Reduced emissions following the economic downturn of recent years only added to this surplus. Finally, Canada's withdrawal from Kyoto, effective in December 2012, increased the surplus further, as Canada would have been a net buyer of Kyoto allowances.

\subsection{Regional greenhouse gas initiative (2009-)}

The RGGI cap-and-trade system covers electricity generators using fossil fuels in nine US states: Connecticut, Delaware, Maryland, Massachusetts, Maine, New Hampshire, New York, Rhode Island, and Vermont. Even before RGGI went into effect, emissions started to decline in the face of two major developments: Switching from coal to gas and demand reduction. First, the shale gas boom in the US made gas more profitable than coal for generating purposes, prompting many generators to switch fuels (Newell et al. 2014; Murray et al. 2014, 10). As in the ARP, much of this switching would have taken place even absent a price on pollution. Second, the recession affected power demand, again reducing the need to burn fossil fuels and thus also demand for RGGI permits. At the end of 2011, the cumulative surplus stood at 186 million short tons, effectively the size of the ten-state cap. To address this imbalance, the participating states in February 2013 proposed to cut the cap by 45 percent starting in 2014 (Regional Greenhouse Gas Initiative 2013). As a result, allowance prices have increased from US \$1.93/ton in 2012 (the floor price) to US \$5.02 in the June 2014 auction (Regional Greenhouse Gas Initiative 2014).

Unlike most other cap-and-trade systems, RGGI imposes a price floor that ensures a minimum incentive to reduce emissions even in the presence of a large allowance surplus. If market participants fail to buy all the allowances offered at an auction, the unsold allowances are withheld from the market. Most states earmark proceeds from the auctions for energy efficiency and renewable energy. Thus, the design of RGGI's auctioning system itself contributes to lowering emissions.

\subsection{Tokyo ETS (2010-)}

In 2006, the Tokyo Metropolitan Government (TMG) introduced a target to reduce its GHG emissions by 50 percent by 2050 and 25 percent by 2020 (Rudolph and Kawakatsu 2012). To reach this target, the city in 2002 introduced a program under which 1,000 large emitters were required to monitor and report their GHG emissions on an annual basis. These data served as a precursor of the cap-and-trade system that was introduced in 2010.

The collective target of the Tokyo ETS is to reduce emissions by 17 percent in 201519 under a baseline drawn from three consecutive years freely selected from 2002 to 2007 
(Rudolph and Kawakatsu 2012). The program covers factories, buildings, and other facilities using district heating and cooling. Indirect emissions from power consumption are counted using a uniform conversion factor for the amount of $\mathrm{CO}_{2}$ emitted per unit electricity produced.

In the second year of operation, covered entities achieved a 23 percent aggregate reduction on their baselines, a fact partly explained by energy efficiency measures put in place after the Fukushima nuclear disaster. A second explanation for the surplus is the fact that companies have been permitted to select years with high emission levels as the baselines against which their emission performance is compared. Unexpected reduction measures and generous cap determination are thus the key explanations for Tokyo's ETS surplus.

\section{Discussion}

All the major cap-and-trade programs discussed in this article have shown emissions consistently below the cap. This propensity to emit less than permitted is also reflected in the relationship between price forecasts and actual prices. Price forecasts are available for the ARP, EU ETS, Kyoto, and RGGI. As shown in Fig. 3, forecasts have consistently overestimated future allowance prices.

The inability to foresee future emission cuts does not, however, have uniform roots across the histories of cap-and-trade programs. Rather, different causes are present in different settings and phases.

Cap-setting processes play a major role explaining the gap between emissions and targets in the first phase of the EU ETS, the Kyoto Protocol, and arguably the Tokyo ETS. The EU ETS phase 1, with its spectacular price crash of April 2006, is perhaps the best example. Kyoto's 2008-12 commitment period, particularly with the negative reduction requirements granted to several East European countries and the exit of the US and Canada, also displays clear over-allocation of allowances. In the ARP, $\mathrm{NO}_{x}$ programs, and EU ETS phase 2, by contrast, the caps were set exogenously - as a function of the EU's Kyoto target in the latter case - and were considered fairly tight at the time they were introduced.

Nevertheless, while generous baselines may explain the presence of gaps between emissions and caps, they cannot explain why such gaps tend to widen over time as shown in Fig. 2. This is because caps either decline or remain fixed; they do not become more generous over time. Other explanations are needed.

Changes in economic output played a key role causing surpluses in the second-phase EU ETS and RGGI allowance markets starting in 2009, as recession curbed demand for electricity and industrial goods. The downturn similarly affected most OECD countries, enlarging the surpluses also of Kyoto and Tokyo ETS allowances. By contrast, economic output changes did not significantly affect the ARP or EU ETS phase 1. The ARP surplus was already very large when the financial crisis struck in 2008-09, whereas the first phase of the EU ETS (2005-07) was over by then.

A simple regression analysis of annual emissions-to-cap ratios in the various programs over normalized economic output figures and an annual trend variable shows that heightening (or lowering) economic growth by one percentage point increases (or reduces) the emissions-to-cap ratio by .84 percentage points, all else equal (see Supplementary Table 1). This relationship is significant at the 5.7 percent level $(n=49)$; adding fixed program effects yields a stronger result. The coefficient on the annual trend, which comprises the effects of innovation and complementary policies, sees a reduction of the emissions-to-cap ratio by 


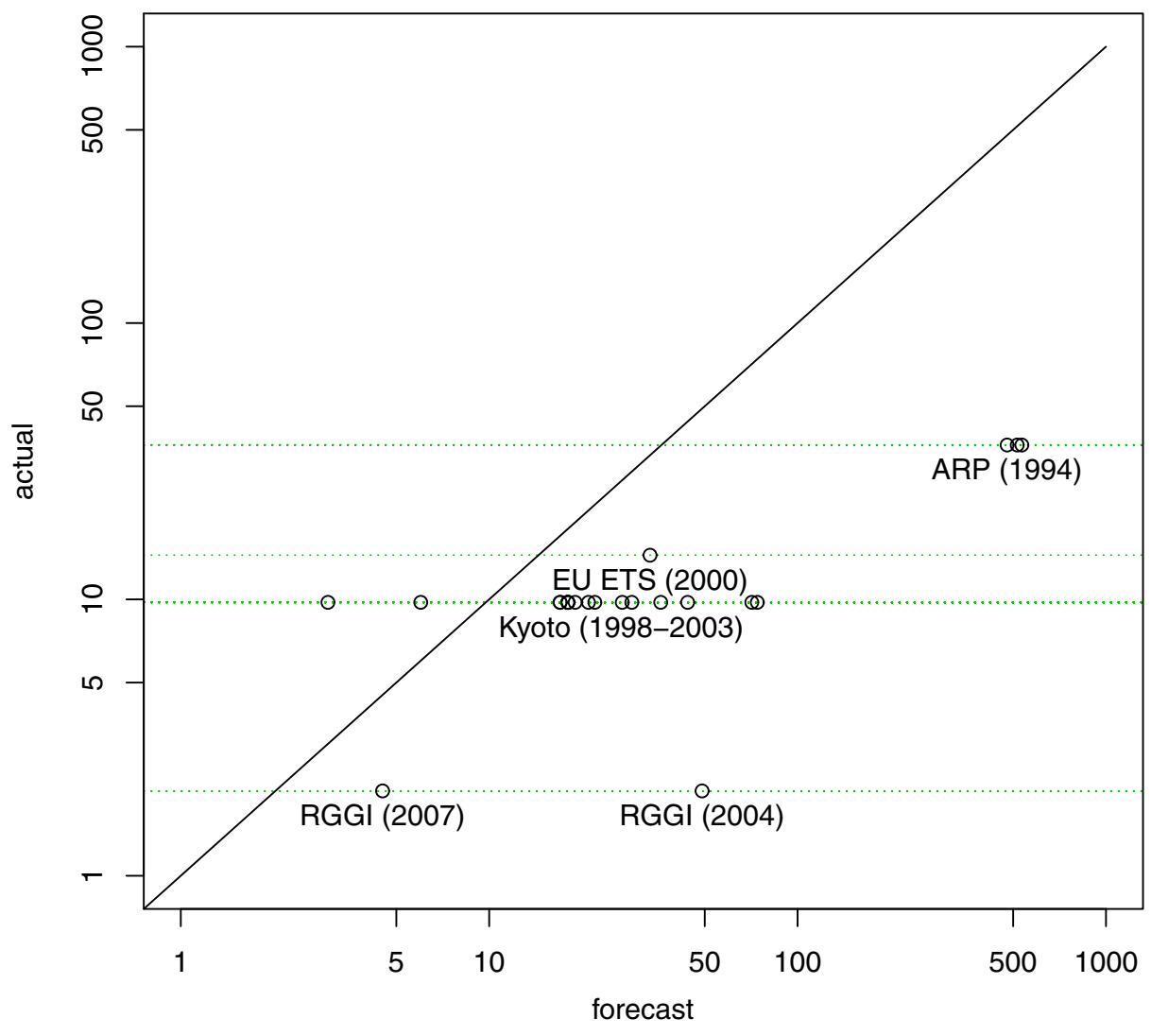

Fig. 3 Price forecasts for 2010 and actual prices in four cap-and-trade programs. The graph shows publicly available price forecasts for 2010. The years in parentheses display when the forecasts were made. ARP price forecasts are reported in Smith et al. (1998); Kyoto forecasts are based on Springer (2003); the EU ETS forecast is taken from the European Commission (2000); RGGI price forecasts are given in Bernstein et al. (2004) and Ruth et al. (2007). The ARP price has been supplied by the United States Environmental Protection Agency (2014). Kyoto, EU ETS and RGGI prices are annual average market prices, supplied by Point Carbon (www.pointcarbon.com)

3.6 percentage points per year, all else equal. This effect is significant at the 2.3 percent level.

The best example of the effects of fuel price changes are seen in RGGI, where the shale gas boom, which was not anticipated in the determination of the RGGI cap, made gas more attractive relative to coal as a fuel for electricity production. Likewise, the increased availability of low-sulfur coal in the early years of the ARP reduced the cost of complying with $\mathrm{SO}_{2}$ caps.

Innovation played a role in securing abatement in the early years of the ARP, as new types of scrubbers were developed and installed. In the EU ETS, the cement sector developed new approaches that had not been foreseen. Granted, innovative behavior to limit emissions constitutes an intended outcome of cap-and-trade (and of emission taxes) as emission pricing policies are measure and technology neutral. However, it is difficult to support the notion that cap-and-trade has produced much more innovation than expected. Based on data from 
US $\mathrm{SO}_{2}$ and $\mathrm{NO}_{x}$ programs, Taylor (2012) shows that patent numbers tend to fall after emission trading starts, as innovators find that research and development is not worth the risk and cost compared to low allowance prices. This suggests that emission pricing on its own does not address the "innovation market failure" that causes suboptimal investment in innovative emission abatement technologies (Goulder 2013, 98).

Complementary policies constitute the most important explanatory factor in recent ARP emission trends, and also play a role in the EU ETS and RGGI. Court decisions imposing stricter emission controls in individual states covered by the ARP have rendered the program more or less defunct, with similar effects seen in the $\mathrm{NO}_{x}$ programs. In the EU ETS and RGGI, support for renewable energy and efficiency has spurred low-carbon innovation and deployment, simultaneously diminishing the isolated effects of the emission caps.

The discussion so far indicates that policymakers have difficulties identifying options, costs, and potential volumes for emission cuts. They thus tend to err on the side of caution when determining emission caps, partly out of general conservatism, partly because the outcome of innovation processes cannot be known in advance, and partly because covered entities have incentives to keep information about abatement potentials private. Projections of abatement potentials and costs thus often suffer from an "end of history illusion" where a smaller amount of change is predicted than has demonstrably taken place in the past (Quoidbach et al. 2013).

The prevalence of caps that turn out to be lenient has prompted calls for new measures to boost permit prices, including emission taxes. How does cap-and-trade compare with emission taxes in effectiveness terms? While apparent mirror images of each other, caps and taxes differ substantially in the areas of performance under uncertainty, political feasibility, and how to deal with exemptions.

First, caps and taxes have different effects when abatement costs deviate from forecasts. The effectiveness of taxes diminishes when abatement costs are higher than expected. Companies will then likely continue to pollute while paying the tax, in principle allowing emissions to rise. Conversely, the effect of caps diminishes with cheaper abatement. Since the empirical record is one of overly "bullish" rather than overly "bearish" abatement cost expectations, the problem of uncertain projections lies more with caps than with taxes.

By contrast, emission caps appear far more politically feasible than emission taxes, as shown by the fact that caps cover a much greater number of jurisdictions and higher volumes of pollution. In particular, the coalition-building propensities of cap-and-trade appear stronger, as environmental and business interests converge (Paterson 2012). The image of cap-and-trade as a durable policy instrument is further buttressed by treating allowances as property rights and by publishing long-term plans for allocation of allowances to regulated firms (Ellerman et al. 2000, 32 n.2). Similarly, efforts to mobilize economic interests behind emission taxes frequently seek to distribute proceeds from the tax to the population at large. Such a approach underlies the British Columbia carbon tax (Jaccard 2012).

Finally, policies imposing emission caps and emission taxes both include concessions and softeners for vulnerable or politically well-positioned entities. In cap-and-trade systems, softeners are provided in the form of free allowances. However, since carbon prices are uniform, incentives to reduce emissions are similar for entities with allowance deficits and surpluses alike. In systems with emission taxes, concessions are typically provided in the form of exemptions or lower tax rates. For example, Sweden provides lower carbon tax rates for industry, agriculture, forestry, and fisheries (Hammar et al. 2013), also reducing incentives to curb emissions. 
In sum, taxes appear better at ensuring abatement when costs fall below expectations, whereas caps show greater political feasibility and robustness. Cap-and-trade with a floor price could be a hybrid solution to this dilemma, combining the safety of an upper limit on emissions when reduction costs are high while ensuring abatement also when costs are low.

\section{Conclusion}

The findings presented here have implications for current debates in the literature, for mitigation policy, and for future climate-related research. First, the observations contribute to the debate about the workings of emission taxes and caps. Specifically, the empirical record shows that cap-and-trade does not yield any "fixed" emission levels. Instead, future discussions should refer to the instrument as imposing emission "ceilings" or maximum limits on long-term cumulative pollution. In most cases, comfortable margins between emissions and caps should be expected.

Second, the findings presented here have implications for the debate over what future emission prices will be needed to reach given temperature targets. For example, the most ambitious IPCC emission scenario and the 2030 EU ETS forecast by market analysts Point Carbon foresee rapidly rising carbon prices as emission targets tighten (van Vuuren et al. 2011; Point Carbon 2014).

What the results of this article suggest, however, is that future emission reduction opportunities may be discovered at lower prices than previously thought, and that ever-rising prices may thus not be an essential component of ambitious climate policy.

Granted, sectors that have so far typically been left out of cap-and-trade (such as land use and transport) may need stronger incentives than those that tend to fall under emission caps (electricity and heavy industry) to produce deep emission reductions. Nevertheless, future projections could benefit from considering the potential for unexpected future lowcost mitigation options.

The fact that absolute emission targets tend to be easier to attain than expected is important for policy, as more abatement is available at an acceptable cost to society. In its pure form, cap-and-trade is not able to capitalize on this abatement potential.

Consequently, cap-and-trade regulations need mechanisms that secure abatement under price uncertainty. A simple mechanism would be an auction reserve or "floor" price, as used in RGGI. Another option is a mechanism regulating the issuance of permits to prevent excessive market swings - a carbon "central bank" (Kaminska 2010).

At the same time, it must be noted that current caps are based on political feasibility rather than global temperature stabilization scenarios. Where caps encourage emission cuts at the margin, stabilization requires decarbonization of key sectors. For example, a major strategy for compliance with cap-and-trade has been switching from coal to gas, which will not suffice under more aggressive scenarios requiring deep cuts in all fossil fuel emissions. While cap-and-trade constitutes a powerful tool for identifying and implementing low-cost mitigation options, the move toward very low and even negative emission levels implied by the most ambitious RCP scenario cannot be achieved only with the low-cost abatement options. Nevertheless, the volume of policy-induced low-cost mitigation options is likely to grow.

Further research should take two principal directions. First, more work needs to be done to estimate the relative contribution of each of the explanatory factors identified as reducing emissions under cap-and-trade programs For example, what is the role of renewable energy promotion compared to that of recession or changes in fuel prices? 
Second, future work on emission scenarios should integrate experience with emission reduction policies that differ across countries, regions, and sectors, nuancing the currently idealized picture of a single global carbon price. A prerequisite for such an update would be more comparative research on how cap-and-trade and similar mitigation policies function in the real world.

Acknowledgments I would like to thank Emilie Mazzacurati, Grant McDermott, the participants at the Uppsala Forum Workshop on Global Climate Change (April 2013), the participants at the Bergen Economics of Energy and Environment Research Conference (May 2013), and two anonymous reviewers for comments and suggestions.

\section{References}

Bernstein PM, Montgomery WD, Tuladhar S (2004) Economic consequences of Northeastern state proposals to limit greenhouse gas emissions from the electricity sector (RGGI). Charles River Associates

Burtraw D, Szambelan SJ (2009) US emissions trading markets for SO2 and NOx, Resources for the Future Discussion Paper no. 09-40

Carlson AE (2009) Iterative federalism and climate change. Nw U L Rev 103:1097

Daley J, Edis T (2010) Markets to reduce pollution: Cheaper than expected. Grattan Institute Report No. 2010-7

Ellerman AD, Joskow PL, Schmalensee R, Montero JP, Bailey EM (2000) Markets for clean air: The US Acid Rain Program. Cambridge University Press, Cambridge

Ellerman AD, Joskow PL, Harrison D (2003) Emissions trading in the US: Experience, lessons, and considerations for greenhouse gases, Report, Pew Center on Global Climate Change

Ellerman AD, Convery FJ, de Perthuis C (2010) Pricing carbon: The European Union emissions trading scheme. Cambridge University Press, Cambridge

Enevoldsen MK, Ryelund AV, Andersen MS (2007) Decoupling of industrial energy consumption and CO2emissions in energy-intensive industries in Scandinavia. Energy Econ 29(4):665-692

European Commission (2000) Green paper on greenhouse gas emissions trading within the European Union

European Parliament and Council of the European Union (2003) Directive 2003/87/EC establishing a scheme for greenhouse gas emission allowance trading within the community and amending Council Directive 96/61/EC

Goulder LH (2013) Markets for pollution allowances: What are the (new) lessons? J Econ Perspect 27(1):87102

Goulder LH, Schein A (2013) Carbon taxes vs. cap and trade: A critical review

Grubb M (2003) The economics of the Kyoto Protocol. World Econ - Henley on Thames 4(3):143-190

Hammar H, Sterner T, Åkerfeldt S (2013) Sweden's $\mathrm{CO}_{2}$ tax and taxation reform experiences. In: Genevey R, Pachauri RK, Tubiana L (eds) Reducing inequalities: A sustainable development challenge, energy and resources institute

Henry LA, Sundstrom LM (2010) Russia and the Kyoto Protocol: From hot air to implementation? In: Harrison K, Sundstrom LM (eds) Global commons, domestic decisions: The comparative politics of climate change. MIT Press, Cambridge, MA, pp 105-137

Jaccard M (2012) The political acceptability of carbon taxes: lessons from British Columbia. In: Milne JE, Andersen MS (eds) Handbook of research on environmental taxation. Edward Elgar Publishing, p 175

Kaminska I (2010) Does Europe need a carbon central bank? FT Alphaville blog. http://ftalphaville.ft.com/ 2010/02/09/145006/does-europe-need-a-carbon-central-bank/

Kriegler E, Weyant J, Blanford G, Krey V, Clarke L, Edmonds J, Fawcett A, Luderer G, Riahi K, Richels R, Rose S, Tavoni M, van Vuuren D (2014) The role of technology for achieving climate policy objectives: overview of the EMF 27 study on global technology and climate policy strategies. Clim Chang 123(34):353-367

Laing T, Sato M, Grubb M, Comberti C (2013) Assessing the effectiveness of the EU Emissions Trading System, Grantham Research Institute on Climate Change and the Environment Working Paper No. 106

Murray BC, Maniloff PT, Murray EM (2014) Why have greenhouse emissions in RGGI states declined? In: An econometric attribution to economic, energy market and policy factors

Newell RG, Pizer WA, Raimi D (2014) Carbon market lessons and global policy outlook. Science 343(6177):1316-1317 
Paterson M (2012) Who and what are carbon markets for? Politics and the development of climate policy. Clim Pol 12(1):82-97

Pigou AC (1920) The economics of welfare. Macmillan, London

Pizer W (2001) Choosing price or quantity controls for greenhouse gases. In: Toman MA (ed) Climate change economics and policy: An RFF anthology. Resources for the Future, Washington, DC, pp 99-107

Point Carbon (2014) Digesting the EU 2030 climate and energy framework - an update to our long-term price forecast. Carbon Market Analyst

Quoidbach J, Gilbert DT, Wilson TD (2013) The end of history illusion. Science 339(6115):96-98

Reed S (2013) In European Union, emissions trade is sputtering. New York Times

Regional Greenhouse Gas Initiative (2005) Memorandum of understanding

Regional Greenhouse Gas Initiative (2013) Summary of RGGI model rule changes. http://www.rggi.org/ docs/ProgramReview

Regional Greenhouse Gas Initiative (2014) Auction results. http://www.rggi.org/market/co2_auctions/results

Rudolph S, Kawakatsu T (2012) Tokyo's greenhouse gas emissions trading scheme: A model for sustainable megacity carbon markets?

Ruth M, Gabriel S, Ross K, Palmer K, Burtraw D, Paul A, Chen Y, Hobbs B, Irani D, Michael J et al (2007) Economic and energy impacts from Maryland's participation in the Regional Greenhouse Gas Initiative. Center for Integrative Environmental Research, University of Maryland, College Park

Schmalensee R, Stavins R (2012) The SO2 allowance trading system: The ironic history of a grand policy experiment

Smith AE, Platt JB, Ellerman AD (1998) The cost of reducing utility SO2 emissions: not as low as you might think, working paper no. 98-010, MIT Center for Energy and Environmental Policy Research

Springer U (2003) The market for tradable GHG permits under the Kyoto Protocol: a survey of model studies. Energ Econ 25(5):527-551

Stern N (2007) The economics of climate change: The Stern review. Cambridge University Press, Cambridge

Taylor MR (2012) Innovation under cap-and-trade programs. P Natl Acad Sci USA 109(13):4804-4809

United States Environmental Protection Agency (2003) NOx Budget Program: 1999-2002 progress report

United States Environmental Protection Agency (2004) NOx budget trading program: 2003 progress and compliance report. http://www.epa.gov/airmarkets/progress/progress-reports.html

United States Environmental Protection Agency (2009) Allowance markets assessment: a closer look at the two biggest price changes in the federal $\mathrm{SO} 2$ and NOx allowance markets

United States Environmental Protection Agency (2012) Clean air interstate rule, acid rain program, and former NOx budget trading program 2011 progress report. http://www.epa.gov/airmarkets/progress/ ARPCAIR11.html

United States Environmental Protection Agency (2014) Annual auction. http://www.epa.gov/airmarkets/ trading/auction.html

van Vuuren DP, Stehfest E, den Elzen MJ, Kram T, van Vliet J, Deetman S, Isaac M, Goldewijk KK, Hof A, Beltran AM et al (2011) RCP2.6: exploring the possibility to keep global mean temperature increase below $2{ }^{\circ} \mathrm{C}$. Clim Chang 109(1-2):95-116 